\title{
25 Research Square \\ Gender Differences in Prognosis after Primary Resection for Retroperitoneal Liposarcoma
}

\section{Cheng-Xin Weng}

Sichuan University West China Hospital

Yu-Han Qi

Sichuan University West China Hospital

Ji-Chun Zhao

Sichuan University West China Hospital

Ding Yuan ( $\nabla$ docyuanding@gmial.com )

Sichuan University West China Hospital https://orcid.org/0000-0002-7430-9890

Yi Yang

Sichuan University West China Hospital

Tie-Hao Wang

Sichuan University West China Hospital

Jia-Rong Wang

Sichuan University West China Hospital

Bin Huang

Sichuan University West China Hospital

\section{Research}

Keywords: Prognosis, Retroperitoneal liposarcoma, Sex

Posted Date: November 1st, 2021

DOI: https://doi.org/10.21203/rs.3.rs-966706/v1

License: (c) (i) This work is licensed under a Creative Commons Attribution 4.0 International License.

Read Full License 


\section{Abstract}

Background: Current evidence regarding gender difference in retroperitoneal liposarcoma (RLPS) is scarce, we sought to investigate whether gender may affect prognosis after primary resection of RLPS.

Methods: We used the Surveillance, Epidemiology, and End Results (SEER) database to identify RLPS patients from January 1973 to December 2015. Multivariate cox proportional hazards analysis was adopted to generate adjusted hazard ratio (AHR) and $95 \%$ confidence intervals $(\mathrm{Cl})$ of survival outcomes.

Results: In total, 2108 RLPS patients, including 971 women and 1137 men, were identified, with a median follow-up of 45.0 (17.0-92.0) months. The 5-year and 10-year overall survival rates were $50.5 \%$ and $31.5 \%$ for men, and $60.4 \%$ and $42.5 \%$ for women. The 5-year and 10 -year disease-specific survival rates for men and women were $71.5 \%, 57.3 \%$ and $76.3 \%, 62.1 \%$, respectively. We found men were associated with an increased risk of all-cause mortality (AHR $1.3,95 \% \mathrm{Cl} 1.0-1.6, \mathrm{P}=.017$ ) but not disease-specific mortality (AHR 1.2, 95\% Cl 0.9-1.6, $\mathrm{P}=.246$ ). The subgroup analyses revealed that men were associated with an increased risk of all-cause mortality in patients with low-grade tumors (AHR 1.8,95\% $\mathrm{Cl} 1.3-2.5$ ) or patients received non-radical resection (AHR 1.6, 95\% Cl 1.2-2.1). Besides, in the subgroup of low-grade tumors, men were also associated with an increased risk of disease-specific mortality (AHR $2.0,95 \% \mathrm{Cl}$ 1.2-3.3).

Conclusion: Men may have worse survival after primary resection of RLPS compared with women, especially in patients with low-grade tumors or patients received non-radical resection. Gender-based disparities may deserve more attention in patients with RLPS.

\section{Introduction}

Liposarcoma is the most common type of soft tissue sarcoma, accounting for approximately $20 \%$ of all mesenchymal neoplasms in adults[1]. Retroperitoneal liposarcoma (RLPS) constituted $10-15 \%$ of all LPSs, also representing the most common (33\%) primary sarcoma to occur in the retroperitoneum[1, 2].

This disease is characterized by various types of adipocytic differentiation[3], which can be classified into four major subtypes: well-differentiated LPS (WDLPS), dedifferentiated LPS (DDLPS), myxoid LPS (MLPS), and pleomorphic LPS (PLPS). The prognoses of LPSs differ according to the primary sites, among which RLPS has the worst prognosis with a 12-year disease-specific survival of $32 \%$ compared to $77 \%-87 \%$ in other parts of the body[4]. Therefore, identifying prognostic factors specifically for RLPS is necessary.

In the recent decade, gender-based differences in tumor biology and prognosis has received increasing attention. In 2013, research in mouse models found gender may distinguish tumor behavior and prognosis in certain genetic alterations[5], which suggested gender may play a subtle role in tumor suppression and oncogenesis, as well as the development of specific subsets of human tumors[6]. In addition, other researchers also observed large gender-based differences in both tumor mutational burden and T-cell inflammation of the cancer microenvironment, which revealed the relationship between gender- 
dimorphism and anticancer immune response[7]. Given increasingly accumulating evidence in genderdisparities in cancer, the 2019 consensus of European Society for Medical Oncology (ESMO) workshop recommended men and women with non-gender related cancers should be considered as biologically distinct groups of patients, for whom specific management strategies merit consideration, especially in diseases with significant differences in outcomes[8]. Therefore, investigation of gender disparities in disease prognosis is fundamental for a better understanding of cancer biology.

In terms of soft tissue sarcomas, only a few studies explored potential gender differences from cell and molecular perspectives $[5,9]$, and there is no evidence showing if there are any gender differences in clinical prognosis, especially in RLPS, the most common subtypes of sarcoma with the poorest prognosis. The present study aimed to conducted a national population-based retrospective cohort study to identify whether gender has an impact on the survival in patients who underwent primary surgery for RLPS. We present the following study in accordance with the STROBE reporting checklist (see Additional file 1).

\section{Materials And Methods}

\section{Data sources}

We retrieved data from the Surveillance, Epidemiology, and End Results (SEER) database for analysis. SEER is a network of population-based cancer registries from geographically different regions in the United States maintained by the National Cancer Institute ( $\mathrm{NCI}$ ), covering $28 \%$ of the US population[10]10. The dataset was extracted from SEER ${ }^{\star S}$ tat Database: 'Incidence - SEER 18 Regs Custom Data (with additional treatment fields), based on the November 2017 submission (1973-2015 varying)'.

\section{Study population}

Our study population included patients diagnosed with LPS primarily found in retroperitoneum between January 1973 and December 2015. We identified study population by cross-referencing anatomical sites (ICD-0-3 Site code:C480) and histology codes (codes related to all subtypes of liposarcoma). Patients with the following ICD.0.3. histological behaviors were selected: 8850/3: Liposarcoma, NOS; 8851/3: Liposarcoma, well differentiated; 8852/3: Myxoid liposarcoma; 8853/3: Round cell liposarcoma; 8854/3: Pleomorphic liposarcoma; 8855/3: Mixed liposarcoma; 8858/3: Dedifferentiated liposarcoma; 8860/3: Angiomyoliposarcoma. We excluded patients who did not receive surgery and patients who were readmitted due to recurrence.

\section{Variables and outcome measures}

The primary exposure variable in this study was gender (men vs women). Other independent variables involved in multivariable regression were age, race, tumor size (diameter larger than $150 \mathrm{~mm}$ or not), histological behaviors (RLPS without specific subtypes, well-differentiated LPS, dedifferentiated LPS, pleomorphic LPS, myxoid/round cell LPS, mixed liposarcoma), summary stages (localized, regional, distant), grade of histology (low-grade vs. high grade, 'Well differentiated; Grade l' and 'Moderately 
differentiated; Grade II' were categorized to low-grade, and 'Poorly differentiated; Grade III' and 'Undifferentiated; anaplastic; Grade IV' were categorized to high-grade), surgical procedures (radical surgery vs. non-radical surgery), chemotherapy (yes or not), radiation therapy (yes or not). The primary outcome was all-cause mortality, and secondary outcome was disease-specific mortality. Survival time was counted from the date of diagnosis of LPS to the date of death or right-censored at the end of followup period.

\section{Statistical analysis}

Continuous variables were described as medians (interquartile ranges) and categorical variables were described as numbers (percentages). The distribution of demographics between the two groups were compared using logistic regression models. For univariate analysis, Kaplan-Meier method and log-rank test were adopted to assess survival outcomes. For multivariate analysis, cox proportional hazard regression models were used to generate adjusted hazard ratio (AHR) and 95\% confidential intervals (CI). Variables included in the multivariate analyses were identified by clinical significance and its impact on the outcome measures in the univariate analysis, i.e. changing the HR by at least $10 \%$ when added into the model.

To address the effect of gender in specific population, we conducted subgroup analysis by age ( $<70$ years and $\geq 70$ years), tumor size ( $\leq 150 \mathrm{~mm}$ and $>150 \mathrm{~mm}$ ), tumor grade (low-grade vs. high grade), histological behaviors (well-differentiated LPS, dedifferentiated LPS, pleomorphic LPS, myxoid/round cell LPS), summary stages (localized, regional, distant) and surgical procedures (radical resection vs. non-radical resection). $P$ values of interactions between gender and each subgroup variables were evaluated using likelihood ratio test by including the interaction terms in the Cox regression model. All statistical analyses were performed using R studio Version 1.2.1335 (http://www.R-project.org) and Empower(R) (www.empowerstats.com, X\&Y solutions, Inc., Boston, MA). All P values were 2-sided, and considered significance at a level of 0.05 .

\section{Results}

\section{Baseline characteristics}

After selection of study population, a total of 2108 RLPS patients involving 1137 (53.9\%) men and 971 $(46.1 \%)$ women were included in our study. The flow diagram was presented in Figure 1. Among the included patients, demographics including race and summary stage were similar between men and women. Therapeutic strategies were also comparable between the two groups regarding surgical procedures, lymph node dissection, perioperative radiation and chemotherapy. However, men were older than women [65(55-72) years vs. 60(51-70) years]. Besides, men had higher proportion of high-grade tumors (39.3\% vs. $30.7 \%)$ but less proportion of tumors larger than $150 \mathrm{~mm}(94.8 \%$ vs $97.1 \%)$. Detailed baseline characteristics were displayed in Table 1. 
Table 1

Baseline characteristics of retroperitoneal liposarcoma patients.

\begin{tabular}{|c|c|c|c|}
\hline Variables & Women $(N=971)$ & Men $(N=1137)$ & P-value \\
\hline Age (years) & $60.0(51.0-70.0)$ & $65.0(55.0-72.0)$ & $<0.001$ \\
\hline Year of diagnosis & $2006(2000-2011)$ & 2007 (2001-2011) & 0.007 \\
\hline Race & & & 0.236 \\
\hline White & 799 (82.6\%) & $954(84.4 \%)$ & \\
\hline Black & $63(6.5 \%)$ & 78 (6.9\%) & \\
\hline Other & $105(10.9 \%)$ & $98(8.7 \%)$ & \\
\hline Histology & & & $<0.001$ \\
\hline NOS & $188(19.4 \%)$ & $191(16.8 \%)$ & \\
\hline Well-differentiated & $346(35.6 \%)$ & $342(30.1 \%)$ & \\
\hline Dedifferentiated & $240(24.7 \%)$ & $393(34.6 \%)$ & \\
\hline Pleomorphic & $50(5.1 \%)$ & $54(4.7 \%)$ & \\
\hline Myxoid/Round cell & $110(11.3 \%)$ & $112(9.9 \%)$ & \\
\hline Mixed & $37(3.8 \%)$ & $45(4.0 \%)$ & \\
\hline Tumor grade & & & $<0.001$ \\
\hline Low-grade & $578(69.3 \%)$ & $597(60.7 \%)$ & \\
\hline High-grade & $256(30.7 \%)$ & $387(39.3 \%)$ & \\
\hline Summary stage & & & 0.548 \\
\hline localized & $478(51.0 \%)$ & $554(50.0 \%)$ & \\
\hline Regional & $376(40.1 \%)$ & $440(39.7 \%)$ & \\
\hline Distant & $83(8.9 \%)$ & $114(10.3 \%)$ & \\
\hline Tumor size (mm) & & & 0.039 \\
\hline$<150$ & $16(2.9 \%)$ & $36(5.2 \%)$ & \\
\hline$\geq 150$ & $541(97.1 \%)$ & $654(94.8 \%)$ & \\
\hline Surgical procedures & & & 0.283 \\
\hline Non-Radical surgery & $598(61.6 \%)$ & $726(63.9 \%)$ & \\
\hline Radical surgery & $373(38.4 \%)$ & $411(36.1 \%)$ & \\
\hline
\end{tabular}




\begin{tabular}{|c|c|c|c|}
\hline Variables & Women $(N=971)$ & Men $(N=1137)$ & P-value \\
\hline Lymph node dissection & & & 0.338 \\
\hline No & $604(63.2 \%)$ & $731(65.3 \%)$ & \\
\hline Yes & $351(36.8 \%)$ & $389(34.7 \%)$ & \\
\hline Radiotherapy & & & 0.057 \\
\hline No & $761(78.4 \%)$ & $851(74.8 \%)$ & \\
\hline Yes & $210(21.6 \%)$ & $286(25.2 \%)$ & \\
\hline Chemotherapy & & & 0.024 \\
\hline No & $897(92.4 \%)$ & 1018 (89.5\%) & \\
\hline Yes & $74(7.6 \%)$ & $119(10.5 \%)$ & \\
\hline $\begin{array}{l}\text { Follow-up time } \\
\text { (months) }\end{array}$ & $51.0(20.5-106.5)$ & $42.0(14.0-82.0)$ & $<0.001$ \\
\hline
\end{tabular}

\section{Univariate analyses for survival outcomes}

The median follow-up time for men and women were 42.0 (14.0-82.0) months and 51.0 (20.5-106.5) months, respectively. The 5 -year and 10 -year overall survival rates were $50.5 \%$ and $31.5 \%$ for men, and $60.4 \%$ and $42.5 \%$ for women. The 5-year and 10 -year disease-specific survival rates for men and women were $71.5 \%, 57.3 \%$ and $76.3 \%, 62.1 \%$, respectively. The survival curves of all-cause mortality and diseasespecific mortality were shown in Figure 2 and Figure 3. Univariate analysis suggested men was associated with a significantly increased risk of all-cause mortality (HR 1.4, 95\% Cl 1.2-1.6, P<0.001) and disease-specific mortality (HR 1.2, 95\% Cl 1.1-1.5, P=0.008). Besides, age, summary stage, grade of histology, lymph node dissection, chemotherapy, and numbers of malignant tumors were also found to be associated with survival outcomes. The survival curves stratified by different subgroups were displayed in Figure 2 and Figure 3.

\section{Multivariate analyses for survival outcomes}

After variable selection, age, histology subtypes, summary stages, tumor sizes, grade of histology, surgical procedures, radiotherapy and chemotherapy were included in the multivariate cox regression model. In adjusted model I (age, histology subtypes and summary stages), men were associated with a significantly increased risk of all-cause mortality (AHR 1.2, 95\% Cl 1.1-1.4, $\mathrm{P}<0.001$ ), but not associated with disease-specific mortality (AHR $1.2,95 \% \mathrm{Cl} 1.0-1.4, \mathrm{P}=0.086$ ). In the fully adjusted model II, the results were similar with adjusted model I, men were also associated with a significantly increased risk of all- 
cause mortality (AHR 1.3,95\% Cl 1.0-1.6, $\mathrm{P}=0.017$ ), but not associated with disease-specific mortality (AHR 1.2, 95\% Cl 0.9-1.6, $\mathrm{P}=0.246$ ). The results of multivariate analyses were shown in Table 2. 
Table 2

Multivariate Cox regression analyses for the effect of gender on the survival outcomes of different population.

\begin{tabular}{|c|c|c|c|c|c|c|c|c|}
\hline & \multicolumn{4}{|c|}{ Overall Survival } & \multicolumn{4}{|c|}{ Disease-specific survival } \\
\hline & \multicolumn{2}{|c|}{ Crude model } & \multicolumn{2}{|c|}{ Adjusted model } & \multicolumn{2}{|c|}{ Crude model } & \multicolumn{2}{|c|}{$\begin{array}{l}\text { Adjusted } \\
\text { model }\end{array}$} \\
\hline & Women & Men & Women & Men & Women & Men & Women & Men \\
\hline Overall cohort ${ }^{a}$ & Ref & $\begin{array}{l}1.4(1.2 \\
1.6)\end{array}$ & Ref & $\begin{array}{l}1.3 \\
(1.0, \\
1.6)\end{array}$ & Ref & $\begin{array}{l}1.2 \\
(1.1, \\
1.5)^{\prime}\end{array}$ & Ref & $\begin{array}{l}1.2 \\
(0.9, \\
1.6)^{\prime}\end{array}$ \\
\hline \multicolumn{9}{|l|}{ Age $^{b}$} \\
\hline$\leq 70$ years & Ref & $\begin{array}{l}1.8(1.4 \\
2.4)\end{array}$ & Ref & $\begin{array}{l}1.4 \\
(1.0, \\
1.8)\end{array}$ & Ref & $\begin{array}{l}1.9 \\
(1.3, \\
2.7)\end{array}$ & Ref & $\begin{array}{l}1.2 \\
(0.9, \\
1.7)^{\prime}\end{array}$ \\
\hline$>70$ years & Ref & $\begin{array}{l}1.2(1.1 \\
1.4)\end{array}$ & Ref & $\begin{array}{l}1.2 \\
(0.8, \\
1.7)\end{array}$ & Ref & $\begin{array}{l}1.1 \\
(0.9, \\
1.3)^{\prime}\end{array}$ & Ref & $\begin{array}{l}1.1 \\
(0.7, \\
1.8)\end{array}$ \\
\hline \multicolumn{9}{|l|}{ Tumor grade ${ }^{c}$} \\
\hline Low-grade & Ref & $\begin{array}{l}1.7(1.4 \\
2.1)\end{array}$ & Ref & $\begin{array}{l}1.8 \\
(1.3, \\
2.5)\end{array}$ & Ref & $\begin{array}{l}1.5 \\
(1.2, \\
1.9)\end{array}$ & Ref & $\begin{array}{l}2.0 \\
(1.2, \\
3.3)\end{array}$ \\
\hline High-grade & Ref & $\begin{array}{l}1.1(0.9 \\
1.4)\end{array}$ & Ref & $\begin{array}{l}1.1 \\
(0.8, \\
1.4)\end{array}$ & Ref & $\begin{array}{l}1.0 \\
(0.8, \\
1.3)\end{array}$ & Ref & $\begin{array}{l}0.9 \\
(0.7 \\
1.3)^{\prime}\end{array}$ \\
\hline \multicolumn{9}{|c|}{ Histological type ${ }^{d}$} \\
\hline $\begin{array}{l}\text { Well- } \\
\text { differentiated }\end{array}$ & Ref & $\begin{array}{l}1.6(1.3 \\
2.1)\end{array}$ & Ref & $\begin{array}{l}1.5 \\
(0.9) \\
2.4)^{\prime}\end{array}$ & Ref & $\begin{array}{l}1.4 \\
(0.9, \\
2.1)\end{array}$ & Ref & $\begin{array}{l}1.5 \\
(0.7 \\
3.3)^{\prime}\end{array}$ \\
\hline Dedifferentiated & Ref & $\begin{array}{l}1.3(1.0 \\
1.6)\end{array}$ & Ref & $\begin{array}{l}1.0 \\
(0.8, \\
1.3)\end{array}$ & Ref & $\begin{array}{l}1.2 \\
(0.9, \\
1.7)^{\prime}\end{array}$ & Ref & $\begin{array}{l}0.9 \\
(0.6, \\
1.3)\end{array}$ \\
\hline $\begin{array}{l}\text { Myxoid/Round } \\
\text { cell }\end{array}$ & Ref & $\begin{array}{l}1.2(0.8 \\
1.6)\end{array}$ & Ref & $\begin{array}{l}1.5 \\
(0.6, \\
3.7)\end{array}$ & Ref & $\begin{array}{l}0.8 \\
(0.5, \\
1.2)\end{array}$ & Ref & $\begin{array}{l}0.7 \\
(0.2, \\
2.3)\end{array}$ \\
\hline \multicolumn{9}{|l|}{ Summary Stage ${ }^{\mathrm{e}}$} \\
\hline Localized & Ref & $\begin{array}{l}1.4(1.2 \\
1.7)\end{array}$ & Ref & $\begin{array}{l}1.2 \\
(0.9, \\
1.8)\end{array}$ & Ref & $\begin{array}{l}1.1 \\
(0.9, \\
1.5)\end{array}$ & Ref & $\begin{array}{l}1.0 \\
(0.6, \\
1.7)\end{array}$ \\
\hline
\end{tabular}


Overall Survival

\begin{tabular}{|c|c|c|c|c|c|c|c|c|}
\hline Regional & Ref & $\begin{array}{l}1.5(1.2 \\
1.8)\end{array}$ & Ref & $\begin{array}{l}1.3 \\
(1.0, \\
1.8)\end{array}$ & Ref & $\begin{array}{l}1.4 \\
(1.1, \\
1.8)\end{array}$ & Ref & $\begin{array}{l}1.3 \\
(0.9, \\
2.0)\end{array}$ \\
\hline Distant & Ref & $\begin{array}{l}1.3(0.9 \\
1.8)\end{array}$ & Ref & $\begin{array}{l}1.5 \\
(0.8 \\
2.9)\end{array}$ & Ref & $\begin{array}{l}1.3 \\
(0.9 \\
2.0)\end{array}$ & Ref & $\begin{array}{l}1.3 \\
(0.6, \\
2.8)\end{array}$ \\
\hline
\end{tabular}

\section{Tumor size ${ }^{f}$}

\begin{tabular}{|c|c|c|c|c|c|c|c|c|}
\hline$<150 \mathrm{~mm}$ & Ref & $\begin{array}{l}1.8(1.2 \\
2.6)\end{array}$ & Ref & $\begin{array}{l}1.4 \\
(0.9, \\
2.2)\end{array}$ & Ref & $\begin{array}{l}1.4 \\
(0.8, \\
2.4)\end{array}$ & Ref & $\begin{array}{l}1.1 \\
(0.6, \\
2.0)\end{array}$ \\
\hline$\geq 150 \mathrm{~mm}$ & Ref & $\begin{array}{l}1.6(1.2, \\
2.0)\end{array}$ & Ref & $\begin{array}{l}1.3 \\
(1.0, \\
1.7)\end{array}$ & Ref & $\begin{array}{l}1.6 \\
(1.2, \\
2.1)\end{array}$ & Ref & $\begin{array}{l}1.3 \\
(0.9, \\
1.7)\end{array}$ \\
\hline
\end{tabular}

\section{Surgical procedure ${ }^{g}$}

\begin{tabular}{|c|c|c|c|c|c|c|c|c|}
\hline Non-radical & Ref & $\begin{array}{l}1.4(1.2 \\
1.6)\end{array}$ & Ref & $\begin{array}{l}1.6 \\
(1.2, \\
2.1)\end{array}$ & Ref & $\begin{array}{l}1.2 \\
(1.0, \\
1.5)\end{array}$ & Ref & $\begin{array}{l}1.5 \\
(1.0, \\
2.2)\end{array}$ \\
\hline Radical & Ref & $\begin{array}{l}1.4(1.1, \\
1.7)\end{array}$ & Ref & $\begin{array}{l}1.0 \\
(0.7, \\
1.4)\end{array}$ & Ref & $\begin{array}{l}1.3 \\
(1.0, \\
1.7)\end{array}$ & Ref & $\begin{array}{l}1.0 \\
(0.6, \\
1.5)\end{array}$ \\
\hline
\end{tabular}

Outcome measures were expressed as HR $(95 \% \mathrm{Cl})$. Ref $=$ reference.

a Adjusted for age, histological type, summary stage, tumor grade, tumor size, surgical procedures, radiotherapy, chemotherapy.

${ }^{b}$ Adjusted for histological type, summary stage, tumor grade, tumor size, surgical procedures, chemotherapy.

${ }^{\mathrm{c}}$ Adjusted for age, histological type, summary stage, tumor size, surgical procedures, chemotherapy.

d Adjusted for age, summary stage, tumor grade, tumor size, surgical procedures, chemotherapy.

e Adjusted for age, histological type, tumor grade, tumor size, surgical procedures, chemotherapy.

${ }^{f}$ Adjusted for age, histological type, summary stage, tumor grade, surgical procedures, chemotherapy.

${ }^{g}$ Adjusted for age, histological type, summary stage, tumor grade, tumor size, chemotherapy.

\section{Subgroup analysis by age}

To test whether the effect of gender may differ in the elderly population older than 70 years, we performed subgroup and interaction analysis by age in the multivariate model adjusting for histology behavior, summary stages, grade of histology, tumor size, surgical procedures and chemotherapy. While 
no gender-based difference in survival was found in the subgroup of patients older than 70 years old, we found men were associated with an increased risk of all-cause mortality (AHR 1.4, 95\% Cl 1.0-1.8, $\mathrm{P}=0.024$ ) but not disease-specific mortality (AHR 1.2, 95\% Cl 0.9-1.7, $\mathrm{P}=0.266$ ) in patients younger than 70 years.

\section{Subgroup analysis by tumor grade}

In addition, to address the potential interaction effect of histology grades with gender on survival, we further performed subgroup and interaction analysis regarding grade of histology in the multivariate adjusted model. After adjusting for age, histology behavior, tumor size, summary stages, surgical procedures and chemotherapy, we did not observe significant association between men and all-cause mortality (AHR 1.1, 95\% Cl 0.8-1.5, P=0.494) or disease-specific mortality (AHR 1.1, 95\% Cl 0.8-1.6, $\mathrm{P}=0.447$ ) in the subgroup of high-grade tumors. However, in terms of patients with low-grade tumors, we found men was associated with significantly increased risks with both all-cause mortality (AHR 1.8, $95 \% \mathrm{Cl} 1.3-2.5, \mathrm{P}<0.001$ ) and disease-specific mortality (AHR 2.1, 95\% Cl 1.2-3.4, $\mathrm{P}=0.005$ ). Besides, significant interaction effect between grade of histology and gender on all-cause mortality was found $(P$ for interaction=0.04).

\section{Subgroup analysis by tumor size}

In the multivariate model adjusted for age, histology behavior, grade of histology, summary stages, surgical procedures and chemotherapy, we performed subgroup analyses stratified by tumor size. The results revealed that men were associated with both increased risks of all-cause mortality (AHR 1.3, $95 \% \mathrm{Cl} 1.0-1.7, \mathrm{P}=0.028$ ) and disease-specific mortality (AHR 1.5, 95\% $\mathrm{Cl} 1.1-2.1, \mathrm{P}=0.015$ ) in patients with tumor larger than $150 \mathrm{~mm}$. By comparison, no association between gender and survival outcomes were found in patients with tumor smaller than $150 \mathrm{~mm}$.

\section{Subgroup analysis by surgical procedure}

We also performed subgroup analysis stratified by surgical procedure in the multivariate model adjusted for age, histology behavior, grade of histology, tumor size, summary stages and chemotherapy. Men were found to be associated with increased risks of all-cause mortality (AHR 1.6, 95\% $\mathrm{Cl} 1.2-2.2, \mathrm{P}=0.001$ ) and disease-specific mortality (AHR 1.7, 95\% Cl 1.1-2.5, P=0.011) in patients who underwent non-radical resection. As for patients received radical tumor resection, no association between gender and all-cause mortality, as well as disease-specific mortality was observed. A test of interaction between surgical procedures and gender on all-cause mortality was statistically significant $(P=0.029)$. The results of other subgroup and interaction analyses were summarized in Figure 4.

\section{Discussion}

In this study, we analyzed SEER data to investigate the effect of gender on survival of patients who underwent primary surgical resection of RLPS. Our results revealed that men were associated with an increased risk of all-cause mortality, but not disease-specific mortality, after primary resection of RLPS in 
overall population. However, in patients with low-grade tumors, men were associated with increased risks of both all-cause mortality and disease-specific mortality after surgery. And these gender differences were more pronounced in patients who underwent non-radical surgery.

Given the rarity of the disease, no specific guideline for RLPS has been established yet. The most recent consensus was built by Trans-Atlantic RPS Working Group in 2015, focusing on the management of primary retroperitoneal sarcoma (RPS) in the adult[11]. The consensus provided detailed perioperative management strategies of RPS, but did not cover the prognostic values of basic characteristics of the patients. Though increasing numbers of studies have suggested gender disparities may play important roles in cancer biology and prognosis, only few studies have examined the role of gender in the prognosis of RLPS. Moore Dalal et al built a nomogram to predict survival outcomes in 801 LPS patients, and gender was identified as a predicting factor for overall LPS4. However, the nomogram also suggested the primary site of LPS strongly affected the prognosis, and RLPS represented the worst subtypes4.

Therefore, identification of the role of gender specifically in the prognosis of RLPS is necessary. The following studies only performed nomograms for patients with primarily resected or recurrent retroperitoneal sarcomas, and gender was not identified as one of the predictors of survival[12, 13]. The results of our study are clinically significant, for the sample size is the largest up to date and they fill the gap concerning the impact of gender disparities on the prognosis of RLPS.

In the overall population, we found men had a worse overall survival than women after primary resection of RLPS. Similar findings were also found in many other malignant tumors, for instance, melanoma, thyroid, non-small cell lung, gastric and hepatocellular cancers, etc.[14-18]. According to the SEER data, we found male LPS patients were generally older and had a higher proportion of high-grade tumors, which may lead to worse overall survival of male patients in the unadjusted analyses. However, we came to the same conclusion after we adjusted for age, histology, summary stages, tumor sizes, grade, and perioperative interventions. Regarding the potential reasons for survival benefits in women, a recent study found the age standardized rates for the majority of cancer types were greater in men than women in the 50 populations studied, which might suggest that at any given chronological age, the female tissues are physiologically younger than male tissues[19]. Besides, other studies indicated that women's benefits in overall survival may be attributed to women's more responsive inflammatory functioning and men's cardiovascular weakness[20, 21]. Future studies are necessary to further explore the underlying reason for the gender difference in the prognosis of RLPS.

In addition, several noteworthy findings emerged in subgroup analyses. First, as age is usually identified as an important predictor for survival, we tested whether the advantage of better overall survival still existed in elderly female RPLS patients. Our results revealed that the benefit of overall survival in women disappeared in the subgroup older than 70 years old, which might be explained by the equal susceptibility to surgical risks in the elderly patients. Second, surgical procedures seemed to be another interactive factor with gender in the prognosis of RLPS. We found the gender disparity of overall survival was more evident in the patients who underwent non-radical resection, while the survival benefit in women disappeared after radical surgery. This interaction effect may be caused by the strong effect of radical 
surgery on overall survival[22]. Third, though no gender difference in disease-specific mortality was observed in overall population, subgroup analysis stratified by tumor grade indicated that men had a higher risk of disease-specific mortality than women in the subgroup of low-grade tumors with significant interactive effect. These findings may affect clinical practice by suggesting male RLPS patients with lowgrade tumors should be treated and followed with a personalized strategy.

Some limitations existed in our study. First, our study was a retrospective study, subjective to information and selection biases. However, our study had a large sample size with long period of follow-up, which could provide sufficient information. Second, RLPS is characterized by high rate of local recurrence after primary resection, but the SEER database did not present details of recurrence during follow-up. As a potential substitute, the results of disease-specific death in this study might shed light on the tumorrelated adverse outcomes. Third, SEER database did not report surgical margins, which prevented us from evaluating the potential confounding effect of resection completeness in survival outcomes. Fourth, French Federation of Cancer Centers Sarcoma Group (FNCLCC) grading criteria for soft tissue sarcoma was not used due to lack of data, instead our study adopted histology grade of SEER database, which involved four categories: 'Well differentiated; Grade I', 'Moderately differentiated; Grade II', 'Poorly differentiated; Grade III', 'Undifferentiated; anaplastic; Grade IV'. Though not as elaborate as FNCLCC grading criteria, our study could reveal an overall trend in the interaction between pathological information and gender on the prognosis of RLPS.

\section{Conclusions}

In conclusion, this population-based cohort study revealed that men had an increased risk of all-cause mortality after primary resection of RLPS compared with women, which is more evident in patients with low-grade tumors or patients received non-radical resection. No gender difference in disease-specific mortality was found in overall population, however, in patients with low-grade tumors, men also have an increased risk of disease-specific mortality. In future clinical practice, gender-based disparities in the prognosis of RLPS should receive more attention and individualized therapeutic and surveillance plan are warranted, particularly in patients with low-grade tumors or patients received non-radical resection.

\section{Declarations}

\section{Acknowledgments}

The authors are grateful to Dr. Changzhong Chen, Chief Scientific Officer at X \& Y Solutions, Newton Highlands, Massachusetts, for his valuable advice in statistical analysis.

\section{Ethics statement}

The authors are accountable for all aspects of the work in ensuring that questions related to the accuracy or integrity of any part of the work are appropriately investigated and resolved. The study was conducted in accordance with the Declaration of Helsinki (as revised in 2013). Ethical approval was not required due 
to de-identified data from a public database was used and individual consent for this retrospective analysis was waived.

\section{Funding}

Not applicable.

\section{Conflicts of interest}

Not applicable.

\section{Authors' contributions}

For research articles with several authors, a short paragraph specifying their individual contribu-tions must be provided. The following statements should be used "Conceptualization, D.Y. and J.Z.; methodology and software, J.W., C.W. and Y.Q.; validation and formal analysis C.W., Y.Q. and T.W.; writing -original draft preparation, C.W. and Y.Q.; writing-review and editing, D.Y.; All authors have read and agreed to the published version of the manuscript.

\section{Availability of data and materials}

The data that support the findings of this study are available from SEER registry but restrictions apply to the availability of these data, which were used under license for the current study, and so are not publicly available.

\section{Consent for publication}

Not applicable.

\section{References}

1. Dei Tos AP. Liposarcoma: new entities and evolving concepts. Ann Diagn Pathol. United States; 2000;4:252-66.

2. Neville A, Herts BR. CT characteristics of primary retroperitoneal neoplasms. Crit Rev Comput Tomogr. United States; 2004;45:247-70.

3. Lee ATJ, Thway K, Huang PH, Jones RL. Clinical and Molecular Spectrum of Liposarcoma. J Clin Oncol. 2018;36:151-9.

4. Dalal KM, Kattan MW, Antonescu CR, Brennan MF, Singer S. Subtype specific prognostic nomogram for patients with primary liposarcoma of the retroperitoneum, extremity, or trunk. Ann Surg. 2006;244:381-91.

5. Haupt S, Mitchell C, Corneille V, Shortt J, Fox S, Pandolfi PP, et al. Loss of PML cooperates with mutant p53 to drive more aggressive cancers in a gender-dependent manner. Cell Cycle. 2013;12:1722-31. 
6. Di Agostino S, Strano S, Blandino G. Gender, mutant p53 and PML: a growing "affaire" in tumor suppression and oncogenesis. Cell Cycle. 2013;12:1824-5.

7. Conforti F, Pala L, Bagnardi V, Viale G, De Pas T, Pagan E, et al. Sex-based differences of the tumor mutational burden and T-cell inflammation of the tumor microenvironment. Ann. Oncol. Off. J. Eur. Soc. Med. Oncol. England; 2019. p. 653-5.

8. Wagner AD, Oertelt-Prigione S, Adjei A, Buclin T, Cristina V, Csajka C, et al. Gender medicine and oncology: report and consensus of an ESMO workshop. Ann Oncol Off J Eur Soc Med Oncol. England; 2019;30:1914-24.

9. Kehlen A, Greither T, Wach S, Nolte E, Kappler M, Bache M, et al. High coexpression of CCL2 and CX3CL1 is gender-specifically associated with good prognosis in soft tissue sarcoma patients. Int J cancer. United States; 2014;135:2096-106.

10. Surveillance, Epidemiology, and End Results (SEER) Program. Available from: https://seer.cancer.gov/

11. Trans-Atlantic RPS Working Group. Management of primary retroperitoneal sarcoma (RPS) in the adult: a consensus approach from the Trans-Atlantic RPS Working Group. Ann Surg Oncol [Internet]. United States; 2015;22:256-63. Available from: http://www.ncbi.nlm.nih.gov/pubmed/25316486

12. Raut CP, Callegaro D, Miceli R, Barretta F, Rutkowski P, Blay J-Y, et al. Predicting Survival in Patients Undergoing Resection for Locally Recurrent Retroperitoneal Sarcoma: A Study and Novel Nomogram from TARPSWG. Clin Cancer Res. United States; 2019;25:2664-71.

13. Gronchi A, Miceli R, Shurell E, Eilber FC, Eilber FR, Anaya DA, et al. Outcome prediction in primary resected retroperitoneal soft tissue sarcoma: histology-specific overall survival and disease-free survival nomograms built on major sarcoma center data sets. J Clin Oncol. United States; 2013;31:1649-55.

14. Oh Y, Choi S, Cho MY, Nam KA, Shin SJ, Chang JS, et al. Male sex and Breslow thickness are important risk factors for recurrence of localized melanoma in Korean populations. J Am Acad Dermatol. United States; 2020;83:1071-9.

15. Asban A, Chung SK, Xie R, Lindeman BM, Balentine CJ, Kirklin JK, et al. Gender and Racial Disparities in Survival After Surgery Among Papillary and Patients With Follicular Thyroid Cancer: A 45-Year Experience. Clin Med Insights Endocrinol Diabetes. 2019;12:1179551419866196.

16. Zhang W, Jin K, Wang F, Zhangyuan G, Yu W, Liu Y, et al. Differences in the prognostic value of tumor size on hepatocellular cancer-specific survival stratified by gender in a SEER population-based study. United Eur Gastroenterol J. 2019;7:933-41.

17. Li H, Wei Z, Wang C, Chen W, He Y, Zhang C. Gender Differences in Gastric Cancer Survival: 99,922 Cases Based on the SEER Database. J Gastrointest Surg. United States; 2020;24:1747-57.

18. Radkiewicz C, Dickman PW, Johansson ALV, Wagenius G, Edgren G, Lambe M. Sex and survival in non-small cell lung cancer: A nationwide cohort study. PLoS One. 2019;14:e0219206.

19. Dix D. Human Carcinogenesis: The Role of Age and Gender. Anticancer Res. Greece; 2019;39:438591. 
20. Crimmins EM, Shim H, Zhang YS, Kim JK. Differences between Men and Women in Mortality and the Health Dimensions of the Morbidity Process. Clin Chem. 2019;65:135-45.

21. Warraich HJ, Califf RM. Differences in Health Outcomes between Men and Women: Biological, Behavioral, and Societal Factors. Clin Chem. England; 2019;65:19-23.

22. MacNeill AJ, Gronchi A, Miceli R, Bonvalot S, Swallow CJ, Hohenberger P, et al. Postoperative Morbidity After Radical Resection of Primary Retroperitoneal Sarcoma: A Report From the Transatlantic RPS Working Group. Ann Surg. United States; 2018;267:959-64.

\section{Figures}




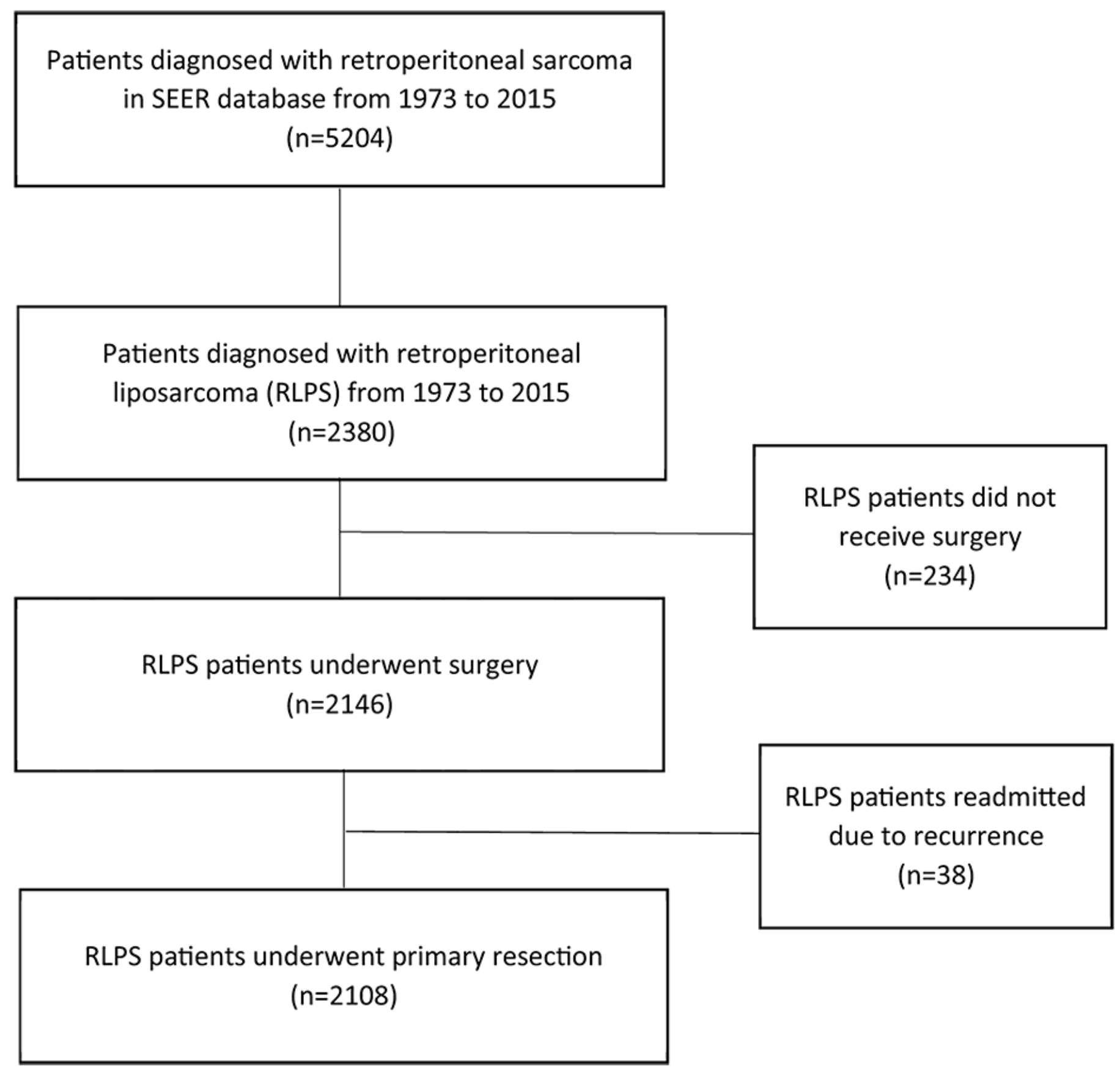

Figure 1

Flow diagram of patient selection. 


\section{A. Overall Survival}
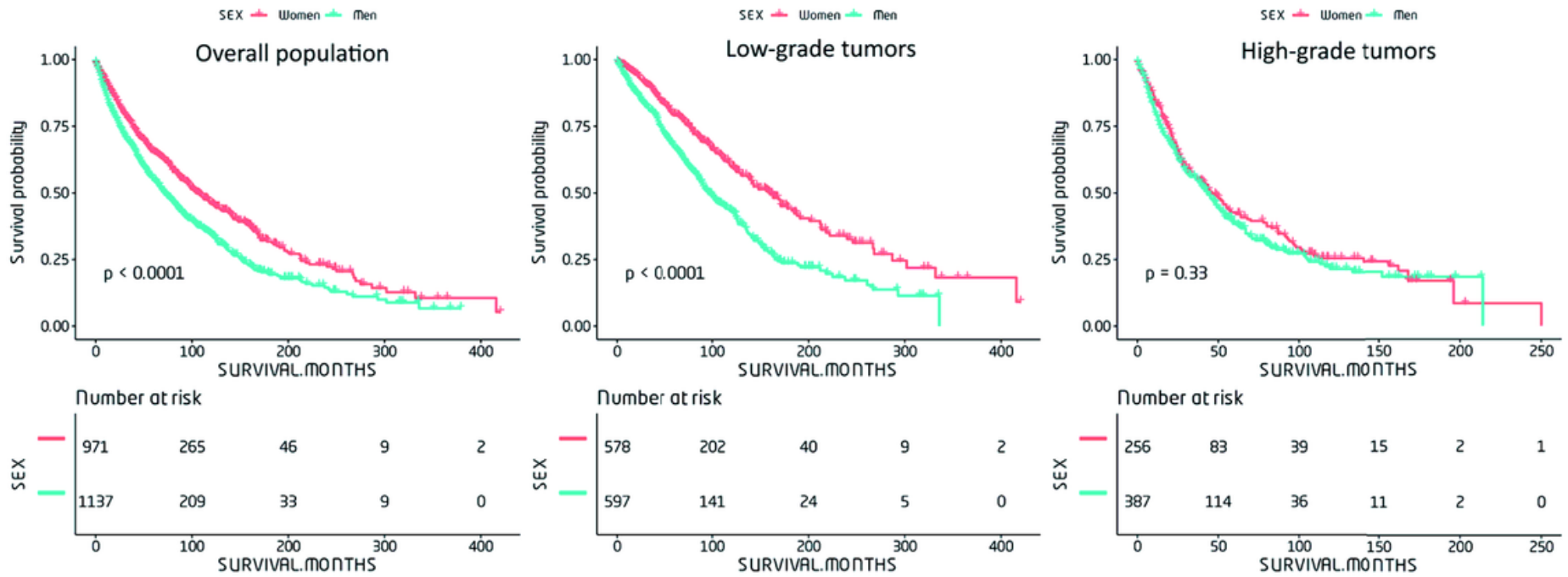

\section{B. Disease-specific survival}
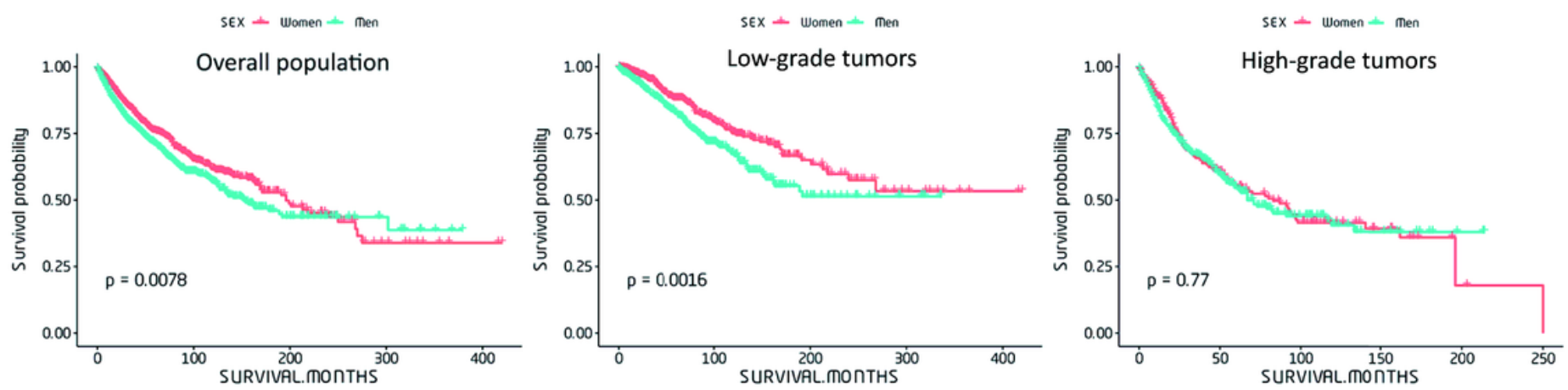

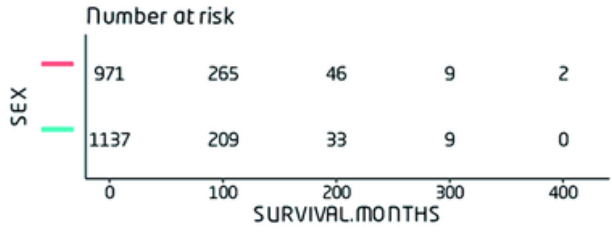
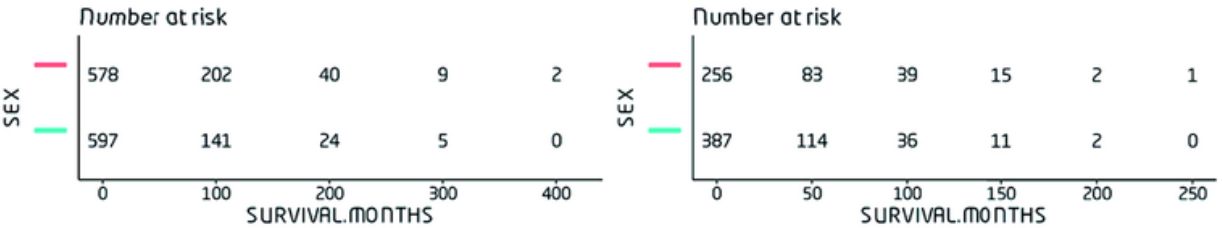

\section{Figure 2}

The Kaplan-Meier curves of overall survival (A) and disease-specific survival (B) in patients who underwent primary resection of retroperitoneal liposarcoma, stratified by histological grade of tumor. 


\section{A. Overall Survival}
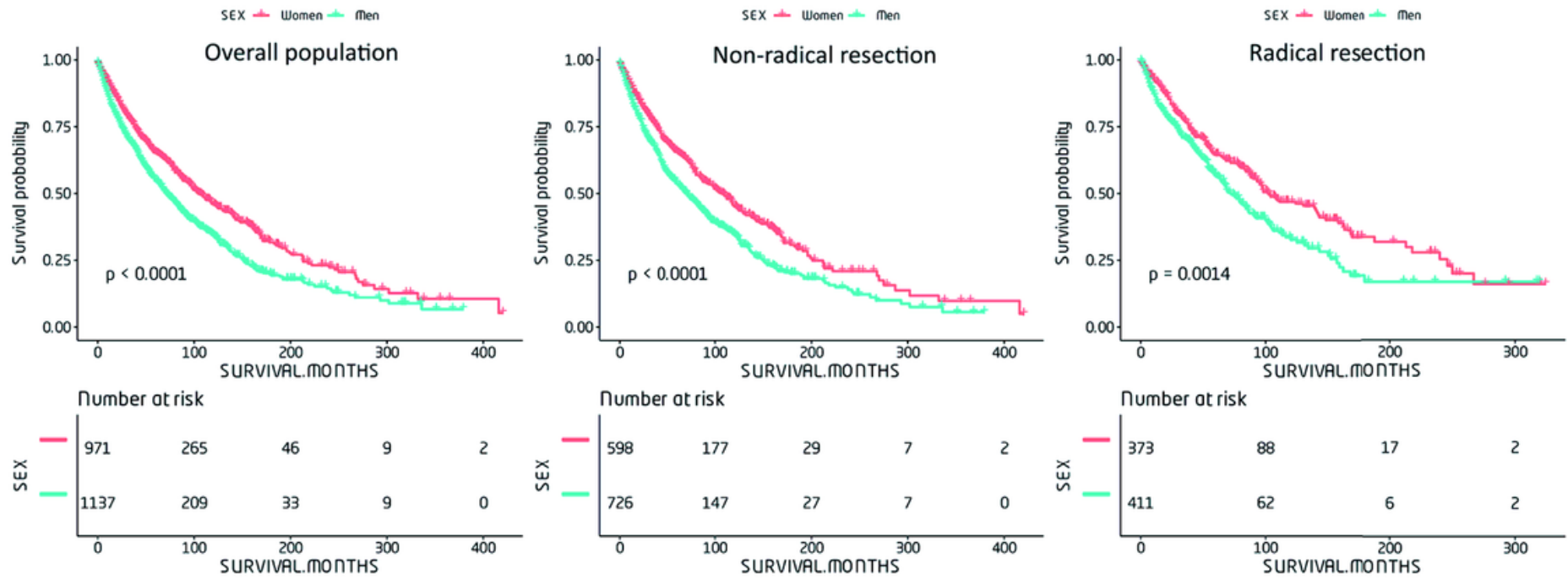

\section{B. Disease-specific survival}
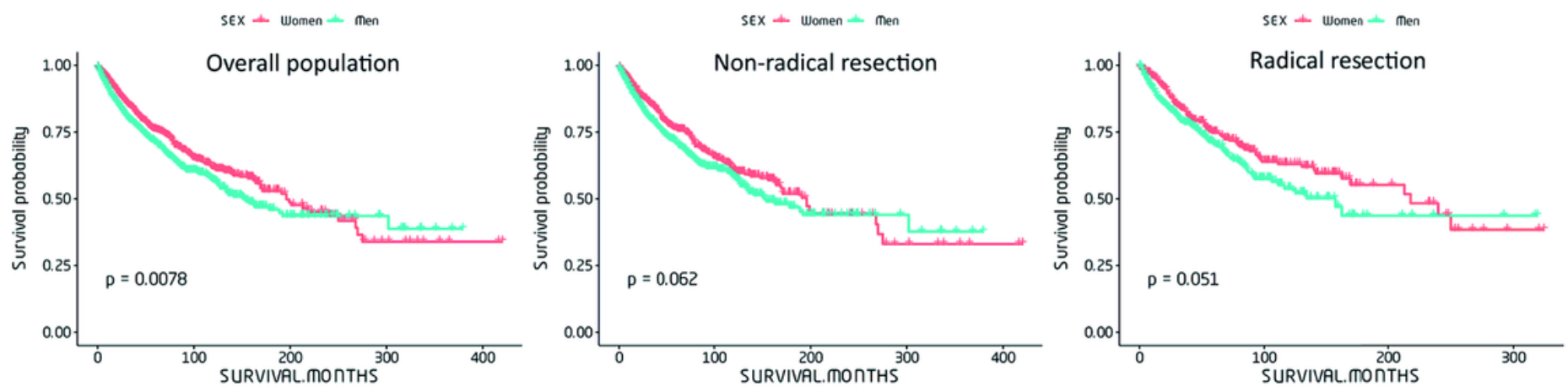

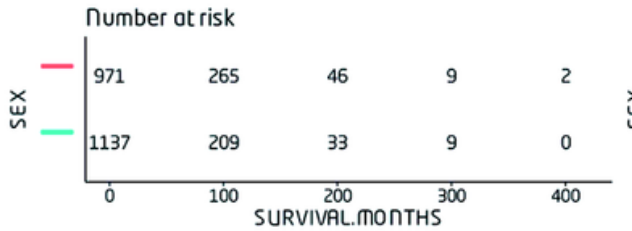
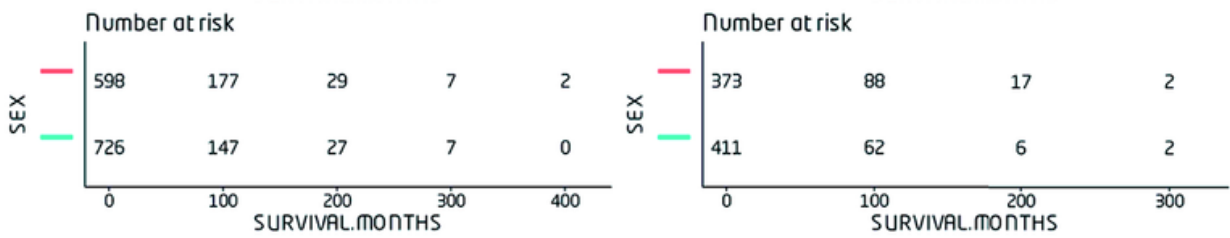

Figure 3

The Kaplan-Meier curves of overall survival (A) and disease-specific survival (B) in patients who underwent primary resection of retroperitoneal liposarcoma, stratified by surgical procedures. 
Subgroup

Age

$\leq 70$ years

$>70$ years

Tumor grade

Low-grode

High-grade

Histological type

Well-differentioted LPS

Dedifferentioted LPS

myxoid/Round cell LPS

Summary Stage

Localized

Regional

Distont

Tumor size

$<150 \mathrm{~mm}$

$\geq 150 \mathrm{~mm}$

Surgical procedure nonrodical resection

Rodical resection

B

\begin{tabular}{|c|c|c|c|c|c|c|}
\hline Subgroup & No. of patients & & HR & $95 \% \mathrm{Cl}$ & P-value & $P$ for Interaction \\
\hline Age & & & & & & 0.525 \\
\hline$\leq 70$ yeors & 794 & $H$ & 1.2 & $(0.9,1.7)$ & 0.266 & \\
\hline$>70$ yeors & 327 & $\mapsto$ & 1.1 & $(0.7,1.8)$ & 0.714 & \\
\hline Tumor grade & & & & & & 0.017 \\
\hline Low-grode & 673 & $\longmapsto$ & 2.0 & $(1.2,3.3)$ & 0.009 & \\
\hline High-grode & 448 & $n$ & 0.9 & $(0.8,1.3)$ & 0.705 & \\
\hline Histological type & & & & & & 0.502 \\
\hline Well-differentioted LPS & 414 & $\longmapsto$ & 1.5 & $(0.7,3.3)$ & 0.341 & \\
\hline Dedifferentioted LPS & 432 & 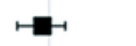 & 0.9 & $(0.6,1.3)$ & 0.701 & \\
\hline Myxoid/Round cell LPS & 60 & $\longrightarrow$ & 0.7 & $(0.2,2.3)$ & 0.576 & \\
\hline Summary Stage & & & & & & 0.524 \\
\hline Locolized & 566 & $\mapsto-$ & 1.0 & $(0.6,1.7)$ & 0.942 & \\
\hline Regionol & 467 & $\mapsto-1$ & 1.3 & $(0.9,2.0)$ & 0.160 & \\
\hline Distont & 88 & $\longmapsto$ & 1.3 & $(0.6,2.8)$ & 0.433 & \\
\hline Tumor size & & & & & & 0.638 \\
\hline$<150 \mathrm{~mm}$ & 354 & $\longmapsto$ & 1.1 & $(0.6,2.0)$ & 0.815 & \\
\hline$\geq 150 \mathrm{~mm}$ & 767 & $r$ & 1.3 & $(0.9,1.7)$ & 0.174 & \\
\hline Surgical procedure & & & & & & 0.103 \\
\hline nonrodicol resection & 627 & $\mapsto$ & 1.5 & $(1.0,2.2)$ & 0.061 & \\
\hline Rodicol resection & 494 & $\mapsto$ & 1.0 & $(0.6,1.5)$ & 0.836 & \\
\hline
\end{tabular}

No. of patients

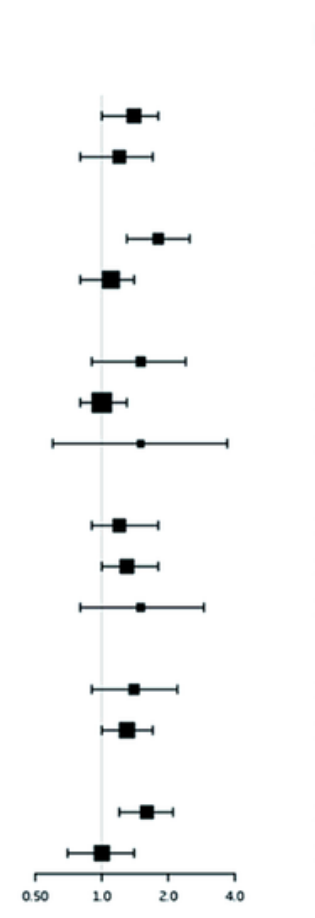

HR

$95 \% \mathrm{Cl}$

1.4

$(1.0,1.8)$

$(0.8,1.7)$

(1.3, 2.5)

$(0.8,1.4)$

$(0.9,2.4)$

$(0.8,1.3)$

$(0.6,3.7)$

(0.9, 1.8)

$(1.0,1.8)$

$(0.8,2.9)$

(0.9, 2.2)

$(1.0,1.7)$

(1.2, 2.1)

$(0.7,1.4)$

0.002

0.914

$P$ for Interaction

0.417

0.022

0.346

0.794

0.632

0.030

627
494

1.0 
This is a list of supplementary files associated with this preprint. Click to download.

- Additionalfile1.docx 